\title{
On the use of a continuous metabolic syndrome score in pediatric
} research

\author{
Joey C Eisenmann
}

Address: Department of Kinesiology, Michigan State University, East Lansing, USA

Email: Joey C Eisenmann - jce@msu.edu

Published: 5 June 2008

Cardiovascular Diabetology 2008, 7:17 doi:10.1 186/1475-2840-7-17

This article is available from: http://www.cardiab.com/content/7/I/I7

(C) 2008 Eisenmann; licensee BioMed Central Ltd.

This is an Open Access article distributed under the terms of the Creative Commons Attribution License (http://creativecommons.org/licenses/by/2.0), which permits unrestricted use, distribution, and reproduction in any medium, provided the original work is properly cited.
Received: 17 April 2008

Accepted: 5 June 2008

\begin{abstract}
Background: The constellation of elevated levels of abdominal adiposity, blood pressure, glucose, and triglycerides and lowered high-density lipoprotein-cholesterol has been termed the metabolic syndrome. Given the current pediatric obesity epidemic, it is perhaps not surprising that recent reports suggest the emergence of the metabolic syndrome during childhood and adolescence. The aim of this paper is to provide an overview of the derivation and utility of the continuous metabolic syndrome score in pediatric epidemiologic research.

Methods/Design: Data were generated from published papers related to the topic.

Conclusion: Although there is no universal definition in children or adolescence, recent estimates indicate that approximately $2-10 \%$ of youth possess the metabolic syndrome phenotype. Since there is no clear definition and the prevalence rate is relatively low, several authors have derived a continuous score representing a composite risk factor index (i.e., the metabolic syndrome score). This paper provides an overview of the derivation and utility of the continuous metabolic syndrome score in pediatric epidemiological research.
\end{abstract}

\section{Background}

The constellation of adverse cardiovascular disease (CVD) and metabolic risk factors, including elevated abdominal obesity, blood pressure, glucose, and triglycerides (TG) and lowered high-density lipoprotein-cholesterol (HDLC), has been termed the metabolic syndrome [1]. Based on the National Cholesterol Education Program Adult Treatment Program III (ATP II) criteria [1] and the International Diabetes Foundation criteria [2] approximately $35 \%$ and $39 \%$, respectively, of U.S. adults possess the metabolic syndrome [3]. In terms of health outcomes, the metabolic syndrome is associated with an increased risk of all-cause mortality, CVD morbidity and mortality, and diabetes [4].
Given the current pediatric obesity epidemic [5], it is perhaps not surprising that recent reports indicate the emergence of the metabolic syndrome during childhood and adolescence [6-10]. Data from the United States (U.S.) National Health and Nutrition Examination Survey (NHANES) III (1988-1994) showed that the prevalence rate of the metabolic syndrome was $4 \%$ in $12-19 \mathrm{yr}$ old adolescents [10]. The prevalence rate increased to $6 \%$ in NHANES 1999-2000 [9]. Based on current estimates, $>2$ million U.S. adolescents have the metabolic syndrome phenotype [9]. Another paper using the same data (i.e., NHANES III) but different criteria showed that the prevalence rate was nearly $10 \%$ [11]. The varying prevalence rates between studies reflects the lack of a universal definition and makes it difficult to draw conclusions. This issue is similar in the adult literature [12]. Prevalence rates 
from representative samples in other countries are limited. The metabolic syndrome in children and adolescents has been reported to be 6.5\% in northern Mexico[13], 9\% in Korea [14], 2\% in Turkey [15], and 10\% in Quebec, Canada [16]. Among obese children and adolescents the prevalence approximates $30-50 \%[10,17,18]$.

Since there is no universal definition of the metabolic syndrome in children or adolescence and the prevalence rate is relatively low, several authors [19-28] have derived a continuous score representing a composite CVD risk factor profile or index (i.e., the metabolic syndrome score). The purpose of this paper is to provide an overview of the derivation and utility of the continuous metabolic syndrome score in pediatric epidemiologic research.

\section{Rationale for a continuous metabolic syndrome score}

The rationale for creating a continuous metabolic syndrome score stems mainly from the fact that there is no clear definition of the metabolic syndrome in children or adolescence and the prevalence rate is relatively low. A low prevalence rate requires a large sample size in order to conduct association studies. For example, in a random sample of 500 U.S. adolescents approximately 15-50 subjects would possess the metabolic syndrome based on current estimated prevalence rates. Thus, the ability to show links between exposures (e.g., physical activity, diet, etc.) and the dichotomous outcome (i.e., metabolic syndrome) using logistic regression would limit the power to detect an association [29].

As mentioned, several authors have derived a continuous score to represent the clustering of components of the metabolic syndrome (Table 1). The inclusion of these key components (i.e., glucose, lipids, blood pressure, and adiposity) is supported by the results of factor analysis in children and adolescents [16,30-32] which shows the underlying patterns or structure among variables showing high degrees of inter-correlation. Thus, there are common variables that can be used to calculate a metabolic syndrome score. It has also been argued that a continuous metabolic syndrome score is statistically more sensitive and less error prone by comparison to the dichotomous approach $[20,29]$. In the recent joint statement by the American Diabetes Association and the European Association for the Study of Diabetes [33], it was recommended that one area of necessary research was the definition of the metabolic syndrome based on continuous variables in a multivariate score system.

\section{An overview of methods used to derive the metabolic syndrome score}

Several large-scale epidemiological studies that either focus on cardiovascular health or include CVD risk factors in children and adolescents have used various approaches

Table I: Summary of approaches used to calculate the continuous metabolic syndrome score in pediatric epidemiological research.

\begin{tabular}{|c|c|c|c|c|c|c|}
\hline$\underline{\text { Study }}$ & Obesity & Lipids & Glucose or $\underline{\text { Insulin }}$ & Blood Pressure & Other & Statistical approach \\
\hline $\begin{array}{l}\text { Bogolusa Heart Study } \\
{[21]}\end{array}$ & - & TC:HDL & Insulin & SBP & & $\begin{array}{l}\text { Sum of the individual } \\
\text { rankings by age-, sex-, } \\
\text { and race-specific levels }\end{array}$ \\
\hline Young Danes [28] & Skinfolds & TC, HDL-C, TG & - & SBP and DBP & smoking & Upper centiles \\
\hline $\begin{array}{l}\text { Cardiovascular Risk } \\
\text { in Young Finns [22] }\end{array}$ & - & $\mathrm{TC}$ and $\mathrm{HDL}-\mathrm{C}$ & - & DBP & & Upper tertile \\
\hline $\begin{array}{l}\text { European Youth } \\
\text { Heart Study [20] }\end{array}$ & Skinfolds & $\mathrm{HDL}-\mathrm{C}$ and TG & Glucose and insulin & $\begin{array}{l}\text { Average of SBP and } \\
\text { DBP }\end{array}$ & & $\begin{array}{l}\text { Sum of six } Z \text { scores } \\
\text { divided by } 6\end{array}$ \\
\hline $\begin{array}{l}\text { European Youth } \\
\text { Heart Study [19] }\end{array}$ & Skinfolds & TG and TC:HDL-C & HOMA & SBP & Aerobic fitness & Sum of $Z$ scores \\
\hline $\begin{array}{l}\text { Corpus Christi Child } \\
\text { Heart Study [23] }\end{array}$ & $\mathrm{BMI}$ & $\mathrm{HDL}-\mathrm{C}$ and $\mathrm{TG}$ & Insulin & SBP & & $\begin{array}{l}2 \text { approaches: I) sum } \\
\text { of } Z \text { scores, and } 2 \text { ) } \\
\text { principal components } \\
\text { analysis }\end{array}$ \\
\hline $\begin{array}{l}\text { Quebec Family Study } \\
{[24]}\end{array}$ & Skinfolds & $\begin{array}{l}\text { HDL-C, TG, and } \\
\text { TC:HDL-C }\end{array}$ & Glucose & MAP & & $\begin{array}{l}\text { principal component } \\
\text { analysis }\end{array}$ \\
\hline $\begin{array}{l}\text { Aerobic Center } \\
\text { Longitudinal Study } \\
\text { [27] }\end{array}$ & WC & HDL-C and TG & Glucose & MAP & & $\begin{array}{l}\text { Sum of age- } \\
\text { standardized residuals }\end{array}$ \\
\hline $\begin{array}{l}\text { Australian Health and } \\
\text { Fitness Study [34] }\end{array}$ & WC & HDL-C and TG & - & MAP & & $\begin{array}{l}\text { Sum of age- } \\
\text { standardized residuals }\end{array}$ \\
\hline $\begin{array}{l}\text { Physical Activity } \\
\text { across the } \\
\text { Curriculum [38] }\end{array}$ & WC & HDL-C and TG & HOMA & MAP & & $\begin{array}{l}\text { Sum of age-, sex-, and } \\
\text { race-standardized } \\
\text { residuals }\end{array}$ \\
\hline
\end{tabular}

BMI, body mass index; WC, waist circumference; TC, total cholesterol; HDL-C, high density lipoprotein-cholesterol; TG, triglycerides; HOMA, homeostasis model assessment; SBP, systolic blood pressure; DBP, diastolic blood pressure; MAP, mean arterial pressure. 
to calculate a metabolic syndrome score (Table 1). As shown in Table 1, the variables included in the score and statistical approaches used to derive the score vary considerably. Indicators of obesity range from the body mass index (BMI) to skinfolds to waist circumference (WC), whereas others do not include a measure of adiposity. The same is true for the other components of the metabolic syndrome. To my knowledge, Eisenmann and colleagues are the only ones to use indicators aligned with the adult criteria. More specifically, WC, HDL-C, TG, mean arterial pressure (MAP) and some indicator of abnormal glucose metabolism are used. Besides differences in the variables included in the score, the statistical approaches used to calculate the score also vary considerably. Previous procedures include principal component analysis [23,24], Z scores $[19,20,23,25-27,34]$, and centile rankings $[21,22]$. In addition, a recent study proposed a categorical score referred to as the Metabolic Individual Risk-factor And Clustering Estimation (MIRACLE) score based on family history (early cardiovascular disease, type 2 diabetes, and hypertension), individual history (small for gestational age and ethnic origin), clinical features (BMI, waist circumference $>$ 90th percentile and blood pressure $>$ 95th percentile) and metabolic abnormalities (glucose intolerance or type 2 diabetes) [35].

\section{An example of the calculation of the metabolic syndrome score using the $Z$ score method}

In the past few years, we have used the $\mathrm{Z}$ score approach to calculate the metabolic syndrome score. In this section, some general considerations and the specific methodology of this approach are highlighted.

\section{Step I: Choice of variables to be included in the metabolic syndrome score}

The first step is to choose the variables to be represented in the score. As mentioned, several variables have been used in the calculation of the metabolic syndrome score.
In the opinion of this author, the variables should reflect the adult metabolic syndrome criteria as discussed above. However, some data sets may lack some of the variables consistent with the adult criteria. For example, fasting blood glucose or WC may not have been measured in some studies. In the case where WC is not available, the $\mathrm{BMI}$ or skinfold thickness has been used. Another issue we have faced is deciding upon which blood pressure variable should be used. Instead of using both systolic and diastolic blood pressure (or the average - e.g., Brage et al.), we have chosen MAP to represent blood pressure. Likewise, the inclusion of glucose and/or insulin is a challenge. Since fasting blood glucose is typically normal in youth and even in overweight youth [10], other parameters of insulin resistance should be used. In recent analyses, we and the European Youth Heart Study [19] chose to represent insulin resistance as the homeostasis assessment model of insulin resistance (HOMA)[36].

\section{Step 2: Choice of variables included in the standardization process}

In our previous studies, the individual risk factors have been regressed onto age to account for any age-related differences in the risk factors. Unfortunately, we have not been able to account for biological maturity status. It is recommended to include a biological maturity indicator in this procedure since maturity status also influences the individual risk factors. In addition, other demographic variables, such as sex, ethnicity, and socio-economic status, can be considered here. Again, a decision needs to be made regarding which variables to include in this step. When sufficient numbers of boys and girls or ethnic groups are available, separate analyses can be conducted for sex and ethnicity. On the other hand, if the sample size for these groups is insufficient for group specific analyses, the individual risk factors can be standardized by age, sex, and ethnicity.

Table 2: Example of data and age-, sex-, and race-standardized $Z$ score used in the derivation of the metabolic syndrome score.

\begin{tabular}{|c|c|c|c|c|c|c|c|c|c|c|c|c|c|}
\hline \multirow[b]{2}{*}{ Subject } & \multirow[b]{2}{*}{ Age } & \multirow[b]{2}{*}{ Race } & \multirow[b]{2}{*}{ WC } & \multicolumn{4}{|c|}{ Measured values } & \multicolumn{4}{|c|}{ Standardized residuals (Z scores) } & \multirow[b]{2}{*}{ Z_HDL } & \multirow[b]{2}{*}{ MetS Score } \\
\hline & & & & MAP & HOMA & TG & $\mathrm{HDL}$ & Z_WC & Z_MAP & Z_HOMA & Z_TG & & \\
\hline 1 & 8 & White & 63.8 & 76.0 & 0.53 & 48 & 47 & 0.55 & -0.49 & -0.52 & -1.01 & 0.66 & -0.81 \\
\hline 2 & 8 & White & 70.5 & 85.3 & 3.33 & 119 & 36 & 1.36 & 0.72 & 1.04 & 1.53 & 1.63 & 6.29 \\
\hline 3 & 8 & Hispanic & 78.5 & 80.0 & 3.32 & 104 & 58 & 1.99 & -0.03 & 0.51 & 0.96 & -0.06 & 3.37 \\
\hline 4 & 7 & Black & 45.8 & 72.0 & 0.56 & 62 & 71 & -1.56 & -0.99 & -0.60 & -0.39 & -1.49 & -5.02 \\
\hline *Mean & 7.7 & & 59.3 & 79.7 & 1.58 & 75.5 & 54.4 & & & & & & \\
\hline *SD & 0.6 & & 8.7 & 7.8 & 2.06 & 26.9 & 11.0 & & & & & & \\
\hline
\end{tabular}

WC, waist circumference $(\mathrm{cm})$; MAP, mean arterial pressure $(\mathrm{mm} \mathrm{Hg})$; HOMA, homeostasis assessment model of insulin resistance; TG, triglyerides (mg/dl); HDL, high density lipoprotein-cholesterol (mg/dl); Z, z score; MetS score, metabolic syndrome score.

*Values indicate sample mean and standard deviation (SD) $(n=193$ girls). 


\section{Step 3: Calculation of individual $Z$ scores and the metabolic syndrome score}

Once the decision has been made as to which variables will be included in the score and which variables will be used to standardize the score, the statistical procedures can then be performed. The initial statistical procedure is to standardize the individual metabolic syndrome variables (e.g., WC, MAP, HOMA, HDL-C, and TG) by regressing them onto the selected demographic variables (e.g., age, sex, ethnicity, etc.). Once each metabolic syndrome variable has been regressed onto the independent variables, the standardized residual is saved (e.g., Z_WC, etc.). Since the standardized HDL-C is inversely related to metabolic risk it is multiplied by -1 . The standardized residuals (Z-scores) for the individual risk factors (WC, MAP, HDL-C, TG, and HOMA) are summed to create the metabolic syndrome score. A higher score is indicative of a less favorable metabolic syndrome profile.

For a specific example, Table 2 shows demographic information, values for individual risk factors and the $\mathrm{Z}$ scores for 4 girls participating in a study that included 193 girls and 182 boys ages 7 to 9 years of age [8]. The individual $Z$ scores and the metabolic syndrome score are also illustrated in Figure 1. The metabolic syndrome score was derived by calculating age-, sex-, and race-specific $Z$ scores for WC, MAP, HOMA, HDL-C, and TG and summing the individual $\mathrm{Z}$ scores as described above. The highest metabolic syndrome scores are in subjects 3 and 4, both of whom were obese. Subject 2 displayed positive $Z$ scores for each risk factor. Subject 1 displayed the lowest metabolic syndrome score and had negative $\mathrm{Z}$ scores for each risk factor. It should be noted that a subject could possess both positive and negative $\mathrm{Z}$ scores for various risk factors (Subject 1).

\section{Limitations of the metabolic syndrome score}

A major limitation to the metabolic syndrome score presented in previous studies is that it is sample specific. Therefore, the mean metabolic syndrome score derived in one study cannot be compared to other studies unless the demographic characteristics, distribution of data, and the measures of central tendency and variability are similar in the two samples. The other limitations of previous research have already been mentioned and include the use of different variables and statistical procedures. It is also important to note that most previous studies have not taken into consideration the age- or maturity-related variation in metabolic syndrome risk factors. Finally, the weighting of each individual variable to the final score is considered equal in the $\mathrm{Z}$ score approach. In contrast, factor analysis and principal components analysis calculate the loadings of each variable independently.

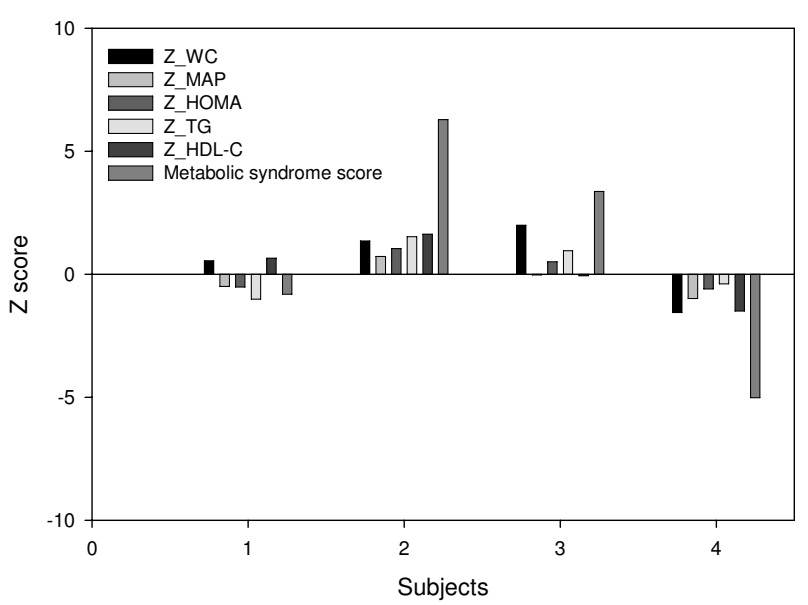

Figure I

Illustrative example of the age-, sex-, and race-standardized $Z$ score used in the derivation of the metabolic syndrome score. See table 2 for abbreviations and measured values.

There is considerable need to develop a universal definition of the pediatric metabolic syndrome [37]. In an excellent review, Cruz and Goran [37] suggested that the same risk factor variables that are used in the adult definition also be used in children so that the definition is consistent across the lifespan for purposes of tracking. In addition, if epidemiological studies are to use the continuous metabolic syndrome score, a standardized method of calculating the score may prove beneficial for comparing studies. An alternative approach to the sample-specific $\mathrm{Z}$ score approach highlighted here may be to compare individual risk factor value to the population median (i.e., $85^{\text {th }}$ percentile of age- and sex-specific reference values) or clinical cut-points.

\section{Utility of the metabolic syndrome score in pediatric epidemiological research}

Several authors have shown significant differences or associations between various exposures and the metabolic syndrome score. For example, results from the Corpus Christi Child Heart Study indicated higher metabolic syndrome scores in Mexican-American boys and girls compared to White boys and girls [23]. Recent studies also show that habitual physical activity and aerobic fitness are inversely associated with the metabolic syndrome score $[19,20,25-27,34]$. Eisenmann and colleagues $[25,26,34,38]$ have also shown that aerobic fitness attenuates the metabolic syndrome score among high fat children and adolescents. The metabolic syndrome score has also been shown to track from childhood/adolescence into young adulthood $[21,22,24,27]$. Other studies show an association between markers of the metabolic syn- 
drome in childhood and type 2 diabetes and cardiovascular disease morbidities in adulthood $[39,40]$. These latter findings hold importance to the predictive utility of the score on disease outcomes and confirms that the definition of the metabolic syndrome in youth and the calculation of the metabolic syndrome score should include the same variables as those in the adult criteria for the metabolic syndrome [37].

\section{Summary and recommendations}

This paper provides an overview of the derivation and utility of the continuous metabolic syndrome score in pediatric epidemiology. The continuous score is important in epidemiological research since there is no universal definition of the metabolic syndrome for children or adolescents and the prevalence rate is relatively low. The score allows each subject to have a continuous value with lower values indicating a better metabolic syndrome profile and higher values indicating a poorer metabolic syndrome profile compared to the sample studied. Several variables and statistical procedures have been used to derive the metabolic syndrome score in previous research (Table 1). It is recommended that the five key metabolic syndrome variables be used in the calculation of the score in future research. These variables include 1) central obesity (as measured by WC - or BMI and/or skin fold thickness if WC is not available), 2) low HDL-C, 3) elevated TG, 4) elevated BP (systolic and/or diastolic and/or MAP), and 5) abnormal glucose metabolism (impaired fasting glucose, impaired glucose tolerance, and/or HOMA). Furthermore, the individual components should be agestandardized (and maturity-standardized, if available) given the influence of growth and maturation on the development of the metabolic risk factors.

Future research is needed to validate the current methodologies used on deriving the metabolic syndrome score in children and adolescents. Recently, Winjndaele et al [41] showed a continuous metabolic syndrome score derived from principal component analysis was higher in adult subjects with the metabolic syndrome and that the score increased progressively with increasing number of adverse risk factors. Although the metabolic syndrome score tracks from adolescence into adulthood [24,42], association studies using established cohorts that link the metabolic syndrome score during childhood and adolescence with adult-diagnosed metabolic syndrome, type 2 diabetes, atherosclerosis and CVD mortality are required. If a simple and practical yet valid method utilizing criterionreference standards can be developed, then the metabolic syndrome score could be used conventionally in pediatric epidemiological research, clinical medicine, and public health to better understand the prevention, diagnosis, and treatment of this emerging pediatric condition.

\section{Competing interests}

The author declares that they have no competing interests.

\section{Authors' contributions}

JCE is the sole author of this manuscript.

\section{Acknowledgements}

The author would like to acknowledge the collaborations with Peter Katzmarzyk, Claude Bouchard, Robert Malina, Greg Welk, Steven Blair, James Dollman, Katrina DuBose, and Joseph Donnelly who have contributed to previous original publications on this topic.

\section{References}

I. National Heart Lung and Blood Institute: Third Report of the National Cholesterol Education Program (NCEP) Expert Panel on Detection, Evaluation, and Treatment of High Blood Cholesterol in Adults (Adult Treatment Panel III): Final Report. Bethesda, MD, National Heart, Lung, and Blood Institute,; 2002.

2. Alberti KG, Zimmet P, Shaw J, IDF Epidemiology Task Force Consensus Group: The metabolic syndrome--a new worldwide definition. Lancet 2005, 366: 1059-1062.

3. Ford ES: Prevalence of the metabolic syndrome defined by the International Diabetes Federation among adults in the U.S. Diabetes Care 2005, 28:2745-2749.

4. Ford ES: Risks for all-cause mortality, cardiovascular disease, and diabetes associated with the metabolic syndrome: a summary of the evidence. Diabetes Care 2005, 28: 1769-1778.

5. Anderson PM, Butcher KE: Childhood obesity: trends and potential causes. Future Child 2006, 16:19-45.

6. Eisenmann JC: Secular trends in variables associated with the metabolic syndrome of North American children and adolescents. Am J Hum Biol 2003, 15:786-794.

7. Weiss R, Dziura J, Burgert TS, Tamborlane WV, Taksali SE, Yeckel CW, Allen K, Lopes M, Savoye M, Morrison J, Sherwin RS, Caprio S: Obesity and the metabolic syndrome in children and adolescents. N Engl J Med 2004, 350:2362-2374.

8. DuBose KD, Stewart EE, Charbonneau SR, Mayo MS, Donnelly JE: Prevalence of the metabolic syndrome in elementary school children. Acta Paediatr 2006, 95: 1005-10II.

9. Duncan GE, Li SM, Zhou XH: Prevalence and trends of a metabolic syndrome phenotype among u.s. Adolescents, 19992000. Diabetes Care 2004, 27:2438-2443.

10. Cook S, Weitzman M, Auinger P, Nguyen M, Dietz WH: Prevalence of a metabolic syndrome phenotype in adolescents: findings From the Third National Health and Nutrition Examination Survey, 1988-1994. Arch Pediatr Adolesc Med 2003, 1 57:82I-827.

II. de Ferranti SD, Gauvreau K, Ludwig DS, Neufeld EJ, Newburger JW, Rifai N: Prevalence of the metabolic syndrome in American adolescents: findings from the Third National Health and Nutrition Examination Survey. Circulation 2004, I I 0:2494-2497.

12. Moebus S, Hanisch JU, Aidelsburger P, Bramlage P, Wasem J, Jöckel $\mathrm{KH}$ : Impact of $\mathbf{4}$ different definitions used for the assessment of the prevalence of the Metabolic Syndrome in primary healthcare: The German Metabolic and Cardiovascular Risk Project (GEMCAS). Cardiovasc Diabetol 2007, 6:22.

13. Rodriguez-Moran M, Salazar-Vazquez B, Violante R, GuerreroRomero F: Metabolic syndrome among children and adolescents aged 10-18 years. Diabetes Care 2004, 27:25।6-2517.

14. Kim HM, Park J, Kim HS, Kim DH: Prevalence of the metabolic syndrome in Korean adolescents aged I2-19 years from the Korean National Health and Nutrition Examination Survey 1998 and 200 I. Diabetes Res Clin Pract 2006.

15. Agirbasli M, Cakir S, Ozme S, Ciliv G: Metabolic syndrome in Turkish children and adolescents. Metabolism 2006, 55:1002-1006.

16. Lambert M, Paradis G, O'Loughlin J, Delvin EE, Hanley JA, Levy E: Insulin resistance syndrome in a representative sample of children and adolescents from Quebec, Canada. Int J Obes Relat Metab Disord 2004, 28:833-84I.

17. Dhuper S, Cohen HW, Daniel J, Gumidyala P, Agarwalla V, St Victor $R$, Dhuper S: Utility of the modified ATP III defined metabolic 
syndrome and severe obesity as predictors of insulin resistance in overweight children and adolescents: a cross-sectional study. Cardiovasc Diabetol 2007, 6:4.

18. Sen Y, Kandemir N, Alikasifoglu A, Gonc N, Ozon A: Prevalence and risk factors of metabolic syndrome in obese children and adolescents: the role of the severity of obesity. Eur J Pediatr 2008, Jan 17 [Epub ahead of print]:.

19. Andersen LB, Harro M, Sardinha LB, Froberg K, Ekelund U, Brage S, Anderssen SA: Physical activity and clustered cardiovascular risk in children: a cross-sectional study (The European Youth Heart Study). Lancet 2006, 368:299-304.

20. Brage S, Wedderkopp N, Ekelund U, Franks PW, Wareham NJ Andersen LB, Froberg K: Features of the metabolic syndrome are associated with objectively measured physical activity and fitness in Danish children: the European Youth Heart Study (EYHS). Diabetes Care 2004, 27:2 |4|-2 I 48.

21. Bao W, Srinivasan SR, Wattigney WA, Berenson GS: Persistence of multiple cardiovascular risk clustering related to syndrome X from childhood to young adulthood. Arch Intern Med 1994, I 54: $1842-1847$.

22. Raitakari OT, Porkka KV, Rasanen L, Ronnemaa T, Viikari JS: Clustering and six year cluster-tracking of serum total cholesterol, HDL-cholesterol and diastolic blood pressure in children and young adults. The Cardiovascular Risk in Young Finns Study. J Clin Epidemiol 1994, 47: 1085-1093.

23. Batey LS, Goff DC], Tortolero SR, Nichaman MZ, Chan W, Chan FA Grunbaum J, Hanis CL, Labarthe DR: Summary measures of the insulin resistance syndrome are adverse among MexicanAmerican versus non-Hispanic white children: the Corpus Christi Child Heart Study. Circulation 1997, 96:4319-4325.

24. Katzmarzyk PT, Perusse L, Malina RM, Bergeron J, Despres J, Bouchard C: Stability of indicators of the metabolic syndrome from childhood and adolescence to young adulthood: the Quebec Family Study. J Clin Epidemiol 200I, 54:190-195.

25. Eisenmann JC, Katzmarzyk PT, Perusse L, Tremblay A, Despres JP, Bouchard C: Aerobic fitness, body mass index and CVD risk factors among adolescents: the Quebec Family Study. Int J Obes 2005, 29:1077-1083.

26. Eisenmann JC, Wickel EE, Welk G, Blair SN: Combined influence of cardiorespiratory fitness and body mass index on cardiovascular disease risk factors among 8 - 18 year old youth: The Aerobics Center Longitudinal Study. Int J Pediatr Obes 2007, 2:66-72.

27. Eisenmann JC, Wickel EE, Welk GJ, Blair SN: Association between cardiorespiratory fitness and fatness during adolescence and cardiovascular disease risk factors in adulthood: the Aerobics Center Longitudinal Study. Am Heart J 2005, 149:46-53.

28. Andersen LB, Haraldsdottir J: Tracking of cardiovascular disease risk factors including maximal oxygen uptake and physical activity from late teenage to adulthood. An 8-year follow-up study. I Internal Med 1993, 243:309-315.

29. Raglund DR: Dichotomizing continuous outcome variables: dependence of the magnitude of association and statistical power of the cutpoint. Epidemiology 1992, 3:434-440.

30. Chen W, Srinivasan SR, Elkasabany A, Berenson GS: Cardiovascular risk factors clustering features of insulin resistance syndrome (Syndrome $X$ ) in a biracial (Black-White) population of children, adolescents, and young adults: the Bogalusa Heart Study. Am J Epidemiol 1999, I 50:667-674.

31. Dwyer T, Blizzard L, Venn A, Stankovich JM, Ponsonby AL, Morley R: Syndrome $X$ in 8-y-old Australian children: stronger associations with current body fatness than infant size or growth. Int J Obes 2002, 26:1301-1309.

32. Moreno LA, Pineda I, Rodriguez G, Fleta J, Giner A, Juste MG, Sarria $A$, Bueno $M$ : Leptin and metabolic syndrome in obese and non-obese children. Horm Metab Res 2002, 34:394-399.

33. Kahn R, Buse J, Ferrannini E, Stern M: The metabolic syndrome: time for a critical appraisal: joint statement from the American Diabetes Association and the European Association for the Study of Diabetes. Diabetes Care 2005, 28:2289-2304.

34. Eisenmann JC, Welk GJ, Ihmels MA, Dollman J: Fitness, fatness and cardiovascular disease risk factors in children and adolescents. Med Sci Sports Exerc 2007, 39:1251-1256.

35. Bueno G, Moreno LA, Bueno O, Morales J, Pérez-Roche T, Garagorri JM, Bueno M: Metabolic risk-factor clustering estimation in obese children. J Physiol Biochem 2007, 63:347-355.
36. Matthews DR, Hosker JP, Rudenski AS, Naylor BA, Treacher DF, Turner RC: Homeostasis model assessment: insulin resistance and beta-cell function from fasting plasma glucose and insulin concentrations in man. Diabetologia 1985, 28:4I2-4I9.

37. Cruz ML, Goran MI: The metabolic syndrome in children and adolescents. Curr Diab Rep 2004, 4:53-62.

38. DuBose K, Eisenmann JC, Donnelly J: Aerobic fitness attenuates the metabolic syndrome score among normal weight, overweight, and obese 7-9 year olds. Pediatrics 2007, I 20:e I 262-8.

39. Morrison JA, Friedman LA, Wang P, Glueck CJ: Metabolic syndrome in childhood predicts adult metabolic syndrome and type $\mathbf{2}$ diabetes mellitus $\mathbf{2 5}$ to $\mathbf{3 0}$ years later. J Pediatr 2008 , I 52:201-206.

40. Juonala M, Viikari JS, Rönnemaa T, Marniemi J, Jula A, Loo BM, Raitakari OT: Associations of dyslipidemias from childhood to adulthood with carotid intima-media thickness, elasticity, and brachial flow-mediated dilatation in adulthood: the Cardiovascular Risk in Young Finns Study. Arterioscler Thromb Vasc Biol 2008, 28:1012-1017.

4I. Wijndaele K, Beunen G, Duvigneaud N, Matton L, Duquet W, Thomis M, Lefevre J, Philippaerts RM: A continuous metabolic syndrome risk score: utility for epidemiological analyses. Diabetes Care 2006, 29:2329.

42. Eisenmann JC, Welk GJ, Wickel EE, Blair SN: Stability of variables associated with the metabolic syndrome from adolescence into adulthood: the Aerobics Center Longitudinal Study. Am J Hum Biol 2004, 16:690-696.
Publish with Biomed Central and every scientist can read your work free of charge

"BioMed Central will be the most significant development for disseminating the results of biomedical research in our lifetime. "

Sir Paul Nurse, Cancer Research UK

Your research papers will be:

- available free of charge to the entire biomedical community

- peer reviewed and published immediately upon acceptance

- cited in PubMed and archived on PubMed Central

- yours - you keep the copyright
BioMedcentral 